\title{
Physician's Role in Preventing Controlled Substance Diversion
}

\section{Jay Porcelli, DO, FACOFP dist.}

San Antonio Regional Hospital

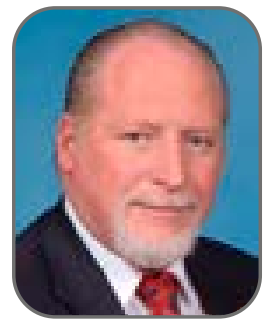

M. Jay Porcelli, DO, FACOFP dist.
CORRESPONDENCE:

M. JayPorcelli, DO, FACOFP dist. ppomando1@msn.com

DOI: $10.38206 / 130105$

\section{KEYWORDS:}

Controlled Substance, Opioids, Pain Management, Substance Diversion

\section{ABSTRACT}

Diversion of opioids and other controlled substances for personal use by physicians poses a risk to patient health, safety and welfare, as well as the health and well-being of the physicians themselves. This article reviews the problem of controlled-substances diversion by physicians and their role in prevention.

\section{INTRODUCTION}

Controlled substance diversion is defined as the illegal distribution or abuse of prescription drugs for unintended purposes by staff or patients, and it puts physicians at regulatory and legal risks. ${ }^{1}$ According to The Centers for Medicare and Medicaid Services (CMS) report, Partners in Integrity, "physicians and other prescribers often have the first opportunity to identify, control, and report drug diversion." 2

\section{PRACTITIONER LAWS AND REGULATIONS}

The Drug Enforcement Agency (DEA) provides the following guidelines to aid practitioners in appropriately prescribing, administering and dispensing controlled substances. These guidelines are intended to educate physicians of their responsibilities in safeguarding the diversion of controlled substances:

\section{$\$ 1306.04$ Purpose of issue of prescription.}

1. To be valid, a prescription for a controlled substance must be issued for a legitimate medical purpose by an individual practitioneracting in the usual course ofhisprofessional practice. ${ }^{3}$

2. The responsibility for the proper prescribing and dispensing of controlled substances is upon the prescribing practitioner, but a corresponding responsibility rests with the pharmacist who fills the prescription. Pharmacists are not obligated to fill the prescription. ${ }^{3}$

3. Practitioners shall provide controls and procedures to guard against the diversion of controlled substances. ${ }^{3}$

According tothe ControlledSubstances Act, physicians can administer, prescribe, or dispense a controlled substance if there is a legitimate medical purpose, and it is done within the usual course 
of professional practice. ${ }^{4}$ The National Institute of Drug Abuse and the DEA identify the top five prescription drugs with the highest potential for diversion and abuse as anabolic steroids, central nervous system depressants, hallucinogens, opioids, and stimulants.

The usual course of professional practice mentioned in the first purpose above is defined as documentation by the practitioner of the patient's medical complaint, the patient's medical history, and by conducting a medical examination. A legitimate medical purpose must be validated by the complaint, history, and examination before a controlled substance should be prescribed.

In the case of opioids, some physicians refuse to treat patients who need these medications to function on a daily basis. For the physicians who do provide care to pain patients and prescribe controlled substances, they need to know how to recognize the signs of controlled substance diversion and prevent it in their practice.

\section{RECOGNIZING DRUG DIVERSION IN YOUR PRACTICE}

There are several signs of controlled substance diversion, and while physicians should approach their patients with trust, they must be aware that patients can be deceptive. Attention must also be paid to employees, other physicians, friends, and family members.

The DEA recommends looking out for the following physician/practice drug diversion red flags in Table 1.

\section{RECOGNIZING DRUG DIVERSION IN YOUR PATIENTS}

A patient encounter isn't adding up. They are claiming to be traveling through town on business or visiting relatives and also requesting an appointment toward the end of the day or after traditional office hours. One common ploy drug diverter's use is to ask to be seen immediately or to be given a prescription right away because they have to "catch a plane" or "get to an important appointment." 6 They may claim that they have lost a paper prescription, forgotten to pack their medication, or had their medication stolen. ${ }^{6}$
TABLE 1.

Physician/Practice Diversion Red Flags ${ }^{5}$

Are state laws followed when prescribing controlled substances?

Multiple drugs prescribed within the same drug category

Patients travel long distances to see this physician

Excessive quantities of controlled substances prescribed relative

to the medical condition being treated

Ignoring signs of patient abuse such as under the influence

Starting patient on high dose

Continued prescribing even though ineffective for treatment purposes

Only treat patients with narcotic controlled substances

Allowing non-medical staff to determine narcotic prescribed -

physician just signs the prescription

Coaching patients on what to say to get the narcotics they want

Violations of own pain management policies and guidelines

Ignore warnings from insurance companies, law enforcement, other physicians

Receiving other compensation for narcotic prescriptions such as sex, guns or drugs

Patient deaths

Ignoring toxicology reports
When patients appear to be extremely well-informed about specific medications and sound like they are reading from a textbook or on the opposite end of the spectrum, mispronouncing drug names to come across as unfamiliar with the controlled substance, proceed with caution and a heightened awareness of other red flags. Another tactic used is posing as government officials or pharmaceutical company representatives. The DEA recommends looking out for the following patient diversion red flags in Table 2.

\section{BEST PRACTICES TO REDUCE RISK}

As a practitioner, your role in the proper prescribing, administering, and dispensing of controlled substances is critical to the patient's health and to safeguard society against the diversion of controlled substances. ${ }^{6} \mathrm{~A}$ comprehensive approach to risk reduction includes taking precautions to minimize controlled substance diversion. 
For patients who use or request a combination of prescriptions to achieve an enhanced effect, proceed with caution and do your due diligence. Patients with extensive pain management might need to be referred to specialized pain practices. ${ }^{7}$ Be sure to extensively document your rationale when prescribing or choosing not to prescribe a controlled substance. ${ }^{7}$ Your DEA or license number needs to be kept secure as to ensure confidentiality (unless disclosure is required.) $)^{7}$ If paper prescriptions are being utilized, move to electronic prescribing as this helps eliminate the theft of prescription pads. Staff education on prescription policies and how to recognize common warning signs of patient drug diversion needs to held regularly along with creating a workplace environment where open communication and compliance are prioritized. ${ }^{7}$

Check to see if there is a State Prescription Drug Monitoring Program in your state and, if possible, start utilizing this resource. Collaborate with pharmacy benefit managers and managed care plans to determine the medical necessity of prescriptions for controlled substances.?

\section{FIGURE 1.}

CMS. gov infographic outlining drug diversion and potential consequences for healthcare workers. ${ }^{11}$

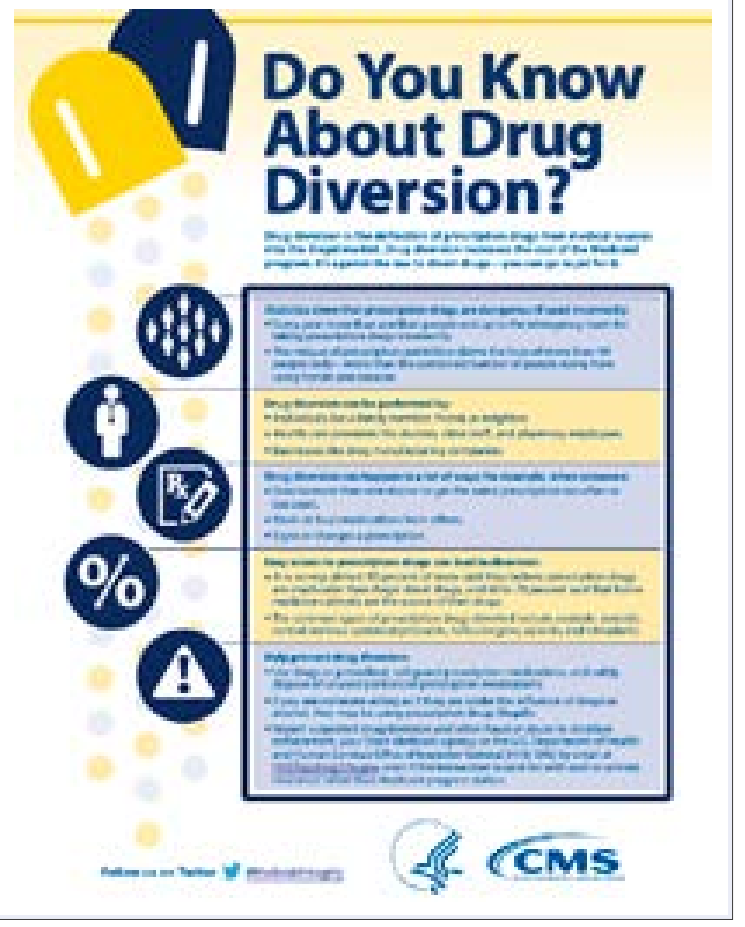

\begin{tabular}{|l|l|}
\multicolumn{2}{l||}{ TABLE 2.} \\
Patient Diversion Red Flags \\
\hline & Refuse medical exam \\
\hline & Brief initial office visits or follow-ups \\
\hline & $\begin{array}{l}\text { Unwilling to give permission to access past medical } \\
\text { records or allow contact with previous providers }\end{array}$ \\
\hline & $\begin{array}{l}\text { Claim they cannot precisely remember where they were } \\
\text { last treated or that the previous clinic }\end{array}$ \\
\hline & $\begin{array}{l}\text { Patients leave the office suddenly if things are not } \\
\text { going their way }\end{array}$ \\
\hline & Unusually high (or low) understanding of medications \\
\hline & Diverters may exaggerate or feign symptoms \\
\hline & $\begin{array}{l}\text { Specific drug requests - } \\
\text { Asking for controlled substances they want }\end{array}$ \\
\hline & Doctor shopping \\
\hline
\end{tabular}

Unused prescription medications and pharmaceutical samples need to be properly disposed. The DEA recommends that physicians initially contact their pharmaceutical sales representatives as many will take back their samples for proper disposal. If the manufacturing company refuses to take back the samples, physicians can contact special authorized collectors known as "reverse distributors." These companies are registered to take all types of drugs back from physicians for the purpose of proper destruction. ${ }^{8}$

For unused prescription medications, physicians and patients can search the DEA's Office of Diversion Control's website database that keeps an updated searchable database of facilities. ${ }^{9}$ Another option is the National Association of Boards of Pharmacy locator tool. ${ }^{10}$ This tool is for patients to check for government entities in their area that have a drug drop box. It should be mandatory to take unused medications to a licensed entity or appropriate government agency for proper disposal in order to minimize any opportunity for controlled substance diversion.

Controlled substances are one of a variety of options for physicians to form the basis of a treatment plan for patients with chronic pain. Each patient is different, and treatment depends on complex factors. Physicians need a regimented and evidenced-based approach to the use of controlled substances in their practice of medicine, as they are both the solution and the problem. 


\section{AUTHOR DISCLOSURES:}

No relevant financial affiliations or conflicts of interest.

\section{REFERENCES:}

1. Centers for Medicare and Medicaid Services. Center for Program Integrity. (2012. January). Drug Diversion in the Medicaid Program: State Strategies for Reducing Prescription Drug Diversion in Medicaid. Retrieved October 15, 2019 from https://www.cms.gov/ Medicare-Medicaid-Coordination/Fraud-Prevention/ MedicaidlntegrityProgram/downloads/drugdiversion.pdf

2. Centers for Medicare and Medicaid Services. What Is a Prescriber's Role in Preventing the Diversion of Prescription Drugs? Retrieved on October 12, 2019 from https://www. cms.gov/medicare-medicaid-coordination/fraud-prevention/ medicaid-integrity-education/provider-educationtoolkits/downloads/prescriber-role-drugdiversion.pdf

3. 36 FR 7799, Apr. 24, 1971. Redesignated at 38 FR 26609, Sept. 24, 1973, and amended at 39 FR 37986, Oct. 25, 1974; 70 FR 36343, June 23, 2005. Retrieved October 12, 2019 from https:// www.deadiversion.usdoj.gov/21cfr/cfr/1306/1306_04.htm.

4. Gabay M. The federal controlled substances act: schedules and pharmacy registration. Hosp Pharm. 2013;48(6):473-474. doi:10.1310/hpj4806-473
5. DEA's Office of Diversion Control. Practitioner Awareness Conference. February 4-5, 2019. Retrieved on January 5, 2020. https://www.deadiversion.usdoj. gov/mtgs/pract_awareness/conf_2019/feb_2019/ brinks2.pdf\#search=diversion\%20tactics\%202019

6. B. Eliot Cole, MD, MPA. Fam Pract Manag. 2001 Oct;8(9):37-41.

7. An Informational Outline of the Controlled Substances Act. Retrieved on October 19, 2019. https://secure. in.gov/pla/files/DEA_Practitioner_Manual.pdf

8. DEA's Office of Diversion Control. Prescriber Role Drug Diversion. Retrieved on October 20, 2019. https://www.cms. gov/medicare-medicaid-coordination/fraud-prevention/ medicaid-integrity-education/provider-educationtoolkits/downloads/prescriber-role-drugdiversion.pdf

9. DEA Office of Diversion Control. Retrieved on October 20, 2019. https://www. deadiversion.usdoj. gov/pubdispsearch/spring/ main?execution $=e 1 s 1$

10. https://nabp.pharmacy/initiatives/awarxe/drugdisposal-locator/. Accessed January 11, 2020.

11. Center for Medicare and Medicaid Services. Retrieved on March 28, 2020. https://www.cms.gov/MedicareMedicaid-Coordination/Fraud-Prevention/MedicaidIntegrity-Education/Downloads/infograph-Do-YouKnow-About-Drug-Diversion-[April-2016].pdf.

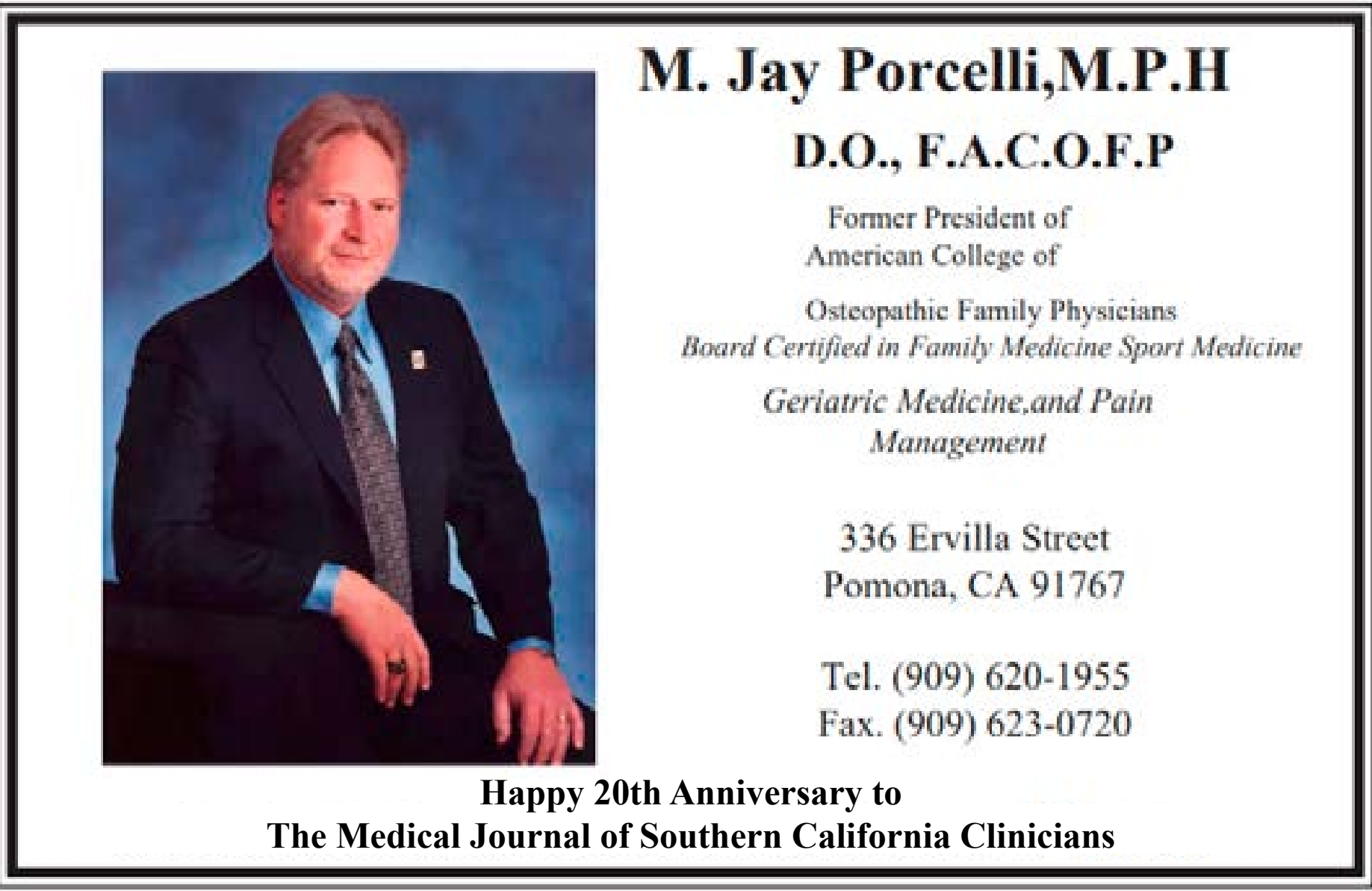

